\title{
FORMULATION AND EVALUATION OF SIMVASTATIN GASTRORETENTIVE DRUG DELIVERY SYSTEM
}

\author{
MANJUNATH P. N. ${ }^{1}$, SATISH C. S. ${ }^{2 *}$, VASANTI S. ${ }^{2}$, PREETHAM A. C. ${ }^{2}$, NAIDU RAS ${ }^{1}$ \\ ${ }^{1}$ Medreich Limited, Maruthi Seva Nagar, Bangalore 560033 India, ${ }^{2}$ Department of Pharmaceutics, PES College of Pharmacy, \\ Hanumanthanagar, Bangalore 560050 India \\ Email: satishcs@hotmail.com
}

Received: 29 Mar 2017, Revised and Accepted: 17 Apr 2017

\begin{abstract}
Objective: The aim of this study was to formulate and evaluate gastro retentive drug delivery system (GRRDS) using an effervescent approach for simvastatin.

Methods: Floating tablets were prepared using directly compressible polymers hydroxypropyl methylcellulose (HPMC) K100M, HPMC K4M and carboxymethylcellulose sodium (NaCMC). The prepared tablets were subjected to pre-formulation studies like Compressibility index, Hausner ratio and post compression parameters like buoyancy/floating test and In vitro dissolution study.

Results: Drug-excipient compatibility studies performed with the help of FTIR instrument indicated that there were no interactions. The DSC thermogram of the formulations revealed that crystalline form of simvastatin existed in the formulation which was confirmed by X-ray powder diffraction. Dissolution studies indicated that there was a decrease in the drug release with an increase in the polymer viscosity. The tablets prepared with low-viscosity grade HPMC K4M exhibited short Buoyancy Lag Time and floated for a longer duration as compared with formulations containing high viscosity grade HPMC K100M. The ' $n$ ' value for dissolution studies for all the formulations was found to be in the range of 0.647 to 0.975 indicating non-Fickian or anomalous drug transport.
\end{abstract}

Conclusion: The drug release rate and floating duration of tablets depended on the nature of the polymer and other added excipients. The release rate of the drug can be optimized by using different ratios of polymers and other excipients. The formulation F8 achieved the optimized batch and complied with all the properties of the tablets.

Keywords: GRRDS, Simvastatin, Polymers, Drug release

(C) 2017 The Authors. Published by Innovare Academic Sciences Pvt Ltd. This is an open access article under the CC BY license (http://creativecommons.org/licenses/by/4.0/) DOI: http://dx.doi.org/10.22159/ijap.2017v9i3.18763

\section{INTRODUCTION}

Atherosclerosis is a general term describing any hardening (loss of elasticity) of the medium of large arteries (in Greek, "Arterio" meaning artery and "sclerosis" meaning hardening), is a condition in which fatty material collects along the walls of arteries. This fatty material thickens, hardens, and eventually blocks the arteries [1]. Simvastatin is a lipid-lowering agent that is derived synthetically from a fermentation product of Aspergillus terreus. After oral ingestion, simvastatin, which is an inactive lactone, is hydrolyzed to the corresponding $\beta$-hydroxyacid form. This is an inhibitor of 3-hydroxy3-methylglutaryl-coenzyme A (HMG-CoA) reductase. This enzyme catalyzes the conversion of HMG-CoA to mevalonate, which is an early and rate-limiting step in the biosynthesis of cholesterol. Also, it has been reported [2,3] that simvastatin is more efficiently extracted by the liver than its corresponding hydroxy acid with subsequent minimization of systemic burden [4]. This suggests that compared to a conventional dosage form, a sustained/controlled release dosage form of simvastatin might provide similar or better efficacy [5].

One of the most feasible approaches for achieving a prolonged and predictable drug delivery in the GI tract is to control the gastric residence time (GRT), i.e. gastro retentive drug delivery system (GRRDS). GRRDS extend significantly the period of time over which the drugs may be released. They not only prolong dosing intervals but also increase patient compliance beyond the level of existing controlled release dosage form [6]. A number of approaches have been used to increase the GRT of a dosage form in stomach by employing a variety of concepts such as Floating Systems [7], Bio/Mucoadhesive Systems [8], and Swelling and expanding systems [9], High-Density Systems [10], Incorporation of passage delaying food agents [11], Ion exchange resins [12], and Osmotic regulated systems [13].

Matrix tablets based on hydroxyl propyl methylcellulose (HPMC K4M) have been developed [14]. Upon contact with gastric fluid, the system takes up water and swell. As the increase in volume is greater than the increase in mass during swelling, the densities of these devices decrease and the system starts to float after a short lag time. The influence of different processing and formulation parameters on the floating properties of matrix tablets has been studied $[15,16]$. Reduced floating lag times could be achieved by reducing the compression forces (thus, increasing tablet porosities), increasing polymer molecular weights and increasing the particle sizes of the matrix-forming polymer [17].

The objective of this study was to develop and optimize GRRDS containing simvastatin as a gastric floating dosage form having a bulk density lower than that of gastric fluids so that it remains buoyant on the stomach contents. To achieve the objective, independent formulation variables such as a drug to total polymer ratio, the polymer to polymer ratio and different viscosity grades of HPMC (K4M, K100M), Carbopol and NaCMC were examined. The dependent variables such as floating time, release profile, hardness and the kinetics and mechanism of drug release for the formulations were studied.

\section{MATERIALS AND METHODS}

\section{Materials}

Simvastatin USP was received as a gift sample from Krebs biochemicals and industries Ltd, Visakhapatnam, India. Carbopol 71G, HPMC K100M and K4M, Citric Acid Anhydrous was received as a gift sample from Colorcon Asia Pvt. Ltd. Sodium CMC was purchased from SD Fine-chem Ltd., Mumbai. Avicel PH 102, DCP anhydrous, Aerosil 200, Sodium Bicarbonate, Magnesium stearate and Talc were purchased from Signet Chemical Corp.

\section{Preparation of gastro retentive tablets}

The composition of different formulations of simvastatin floating tablets is shown in table 1. Gastro retentive tablets containing simvastatin were prepared by direct compression technique using 
variable concentrations of polymers like HPMC K100M, HPMC K4M, carbopol 71G and NaCMC. The respective ingredients (drug, polymer, and additives) were passed through a sieve no. 60 (250 $\mu \mathrm{m}$ ) and blended with a turbula mixer (Analytical Technology,
Bangalore, India). All the batches were compressed on a 10-station tablet machine (Cadmach, Ahmedabad, India) with 7-mm flat round punches. Three batches were prepared for each formulation (table 1).

Table 1: Composition of gastro retentive tablets of simvastatin

\begin{tabular}{|c|c|c|c|c|c|c|c|c|c|c|}
\hline \multirow[t]{2}{*}{ Ingredients } & \multirow[t]{2}{*}{ Sieve no } & \multicolumn{9}{|c|}{ Quantity/tablet in mg } \\
\hline & & F1 & F2 & F3 & F4 & F5 & F6 & F7 & F8 & F9 \\
\hline Simvastatin & $\# 40$ & 60 & 60 & 60 & 60 & 60 & 60 & 60 & 60 & 60 \\
\hline HPMC K100M & \#60 & 80 & 80 & -- & -- & -- & -- & -- & -- & -- \\
\hline Carbopol 71G & $\# 40$ & 20 & -- & -- & -- & -- & -- & -- & -- & -- \\
\hline Sodium CMC & \#60 & -- & 20 & -- & -- & -- & -- & 80 & 20 & 20 \\
\hline HPMC K4M & \#60 & -- & -- & 30 & 60 & 60 & 80 & -- & 80 & 100 \\
\hline Avicel PH 102 & \#40 & 42.8 & 42.8 & 36 & 54 & -- & 62.8 & 62.8 & 42.8 & 22.8 \\
\hline DCP Anhydrous & \#40 & -- & -- & -- & -- & 54 & -- & -- & -- & -- \\
\hline $\mathrm{NaHCo}_{3}$ & $\# 40$ & 50 & 50 & 50 & 50 & 50 & 50 & 50 & 50 & 50 \\
\hline Citric acid anhydrous & \#40 & 16 & 16 & 16 & 16 & 16 & 16 & 16 & 16 & 16 \\
\hline Aerosil 200 & $\# 40$ & 5.6 & 5.6 & 4 & 5 & 5 & 5.6 & 5.6 & 5.6 & 5.6 \\
\hline Talc & $\# 40$ & 2.8 & 2.8 & 2 & 2.5 & 2.5 & 2.8 & 2.8 & 2.8 & 2.8 \\
\hline Magnesium stearate & $\# 40$ & 2.8 & 2.8 & 2 & 2.5 & 2.5 & 2.8 & 2.8 & 2.8 & 2.8 \\
\hline Total(mg) & -- & 280 & 280 & 200 & 250 & 250 & 280 & 280 & 280 & 280 \\
\hline Punch Size (mm) & -- & 9 & 9 & 7 & 8 & 8 & 9 & 9 & 9 & 9 \\
\hline
\end{tabular}

\section{Infrared spectroscopy}

The infrared spectra of simvastatin and formulation were recorded on FTIR (JASCO-FTIR 5300). The samples were prepared on $\mathrm{KBr}$ press (Spectra Lab, Mumbai, India).

\section{Flow properties of granules}

The flow properties of granules were characterized in terms of angle of repose, Carr's consolidation index and Hausner ratio.

\section{DSC (Differential scanning calorimetry)}

The instrument used was Perkin-Elmer DSC-7. Samples were sealed hermetically in a flat bottom aluminum cells. These samples were then heated over a temperature range of $320{ }^{\circ} \mathrm{K}-520^{\circ} \mathrm{K}$ in an atmosphere of nitrogen $(20 \mathrm{~mm} / \mathrm{min})$ at a constant rate of $5{ }^{\circ} \mathrm{C} / \mathrm{min}$ with alumina being reference standard.

\section{X-ray diffraction}

The physical state of simvastatin in the various preparations was evaluated by X-ray diffraction. Powder X-ray diffraction patterns of all samples were determined using Phillips PW 3710 scanner, IW 1830 generator with a CuK $\alpha$ anode at $40 \mathrm{kV}$ and $30 \mathrm{~mA}$ and at a scan rate of $1^{\circ} \mathrm{min}^{-1}$ from $2 \theta$ range from $5^{\circ}$ to $40^{\circ}$.

\section{Buoyancy/floating test}

The time between introduction of the dosage form and its buoyancy on the simulated gastric fluid and the time during which the dosage form remain buoyant were measured. The time taken for the dosage form to emerge on the surface of the medium is called Floating Lag Time (FLT) or Buoyancy Lag Time (BLT) and total duration of time for which dosage form remain buoyant is called Total Floating Time (TFT) [18].

\section{Effect of hardness on buoyancy lag time (BLT) or floating lag time (FLT)}

Formulation F8 was selected to study the effect of hardness on buoyancy lag time. The tablets of batch F8 were compressed at three different compression pressures to get the hardness of $4 \mathrm{~kg} / \mathrm{cm}^{2}, 5$ $\mathrm{kg} / \mathrm{cm}^{2}, 7 \mathrm{~kg} / \mathrm{cm}^{2}$ and $8 \mathrm{~kg} / \mathrm{cm}^{2}$. And were evaluated for Buoyancy Lag Time by following the method as done for Buoyancy test $[19,20]$.

\section{In vitro dissolution study}

Drug release profile was evaluated in-vitro by using a dissolution test apparatus (Electro Lab, TDT-08L, Mumbai, India). The USP XXIII Type II (paddle-type) method was selected to perform the dissolution profile of simvastatin. The dissolution for all the formulations was carried out in $900 \mathrm{ml} 0.1 \mathrm{~N} \mathrm{HCl}$ containing $0.5 \%$ SLS. The temperature was maintained at $37 \pm 0.5{ }^{\circ} \mathrm{C}$ and a constant paddle rotation speed of $50 \mathrm{rpm}$. Samples $(10 \mathrm{ml})$ were withdrawn at regular intervals and filtered through a membrane filter (pore size $0.22 \mu \mathrm{m}$ ). Each sample was analyzed at $239.1 \mathrm{~nm}$ using UV-visible spectrophotometer against reagent blank [21].

\section{RESULTS AND DISCUSSION}

In the present study the floating tablets of simvastatin were prepared by direct compression technique with HPMC K4M, HPMC $\mathrm{K} 100 \mathrm{M}, \mathrm{NaCMC}$, Carbopol as matrix polymers, sodium bicarbonate and citric acid anhydrous were used as a gas generating agent, MCC and DCP were used as a diluents, magnesium stearate and talc as a lubricant and glidant respectively.

\section{Drug-polymer interaction study}

Drug-polymer interaction studies were performed using FTIR spectrophotometer. Characteristics peaks obtained for the pure drug correlated well with that of the formulation peaks. This indicated that the drug was compatible with the formulation components. The FTIR spectra's for the formulation and pure drug is shown in fig. 1. The FTIR spectra's of all samples are shown in fig. 1. The spectrum of pure drug and formulation F-8 presented characteristic peaks at $3553 \mathrm{~cm}^{-1}$ (alcohol O-H stretching vibration), $3011 \mathrm{~cm}^{-1}$ (olefinic C-H stretching vibration), 2957 and $2878 \mathrm{~cm}^{-1}$ (methyl and methylene C$\mathrm{H}$ asymmetric and symmetric stretching vibration), $1719 \mathrm{~cm}^{-1}$ and $1701 \mathrm{~cm}^{-1}$ (Lactone $\mathrm{C}=0$ and ester $\mathrm{C}=0$ stretch), 1453, 1406, and $1383 \mathrm{~cm}^{-1}$ (methyl and methylene bending vibration), 1267, 1222, 1178 , and $1080 \mathrm{~cm}^{-1}$ (lactone and ester C-O-C bending vibration), $1060 \mathrm{~cm}^{-1}$ (secondary alcohol C-0 stretching vibration), and $879 \mathrm{~cm}$ ${ }^{1}$ (trisubstituted olefinic C-H wag), respectively.

\section{Differential scanning calorimetry (DSC)}

To understand the physical state of the drug, DSC was performed on pure drug and formulation F-8 (fig. 2). The DSC thermogram of the formulations revealed that an endothermic peak of melting of simvastatin at about $134.76{ }^{\circ} \mathrm{C}$ was shifted to about $133.97{ }^{\circ} \mathrm{C}$. This suggested that a crystalline form of simvastatin existed in the formulation.

\section{X-ray diffraction}

Powder X-ray diffractograms of pure simvastatin and formulation F8 are shown in fig. 3 . The presence of numerous distinct peaks in the $\mathrm{x}$-ray diffraction spectrum indicated that simvastatin was present as a crystalline material with major characteristic diffraction peaks appearing at a diffraction angle of $2 \theta$ at 7.72, 8.22, 10.81, 14.82, $15.47,16.39,17.12,17.57,18.69,19.28,21.93,22.52,25.80,28.24$ and 31.91. Formulation F-8 showed similar major characteristic diffraction peaks indicating the existence of simvastatin in crystalline form in the formulation F-8. 


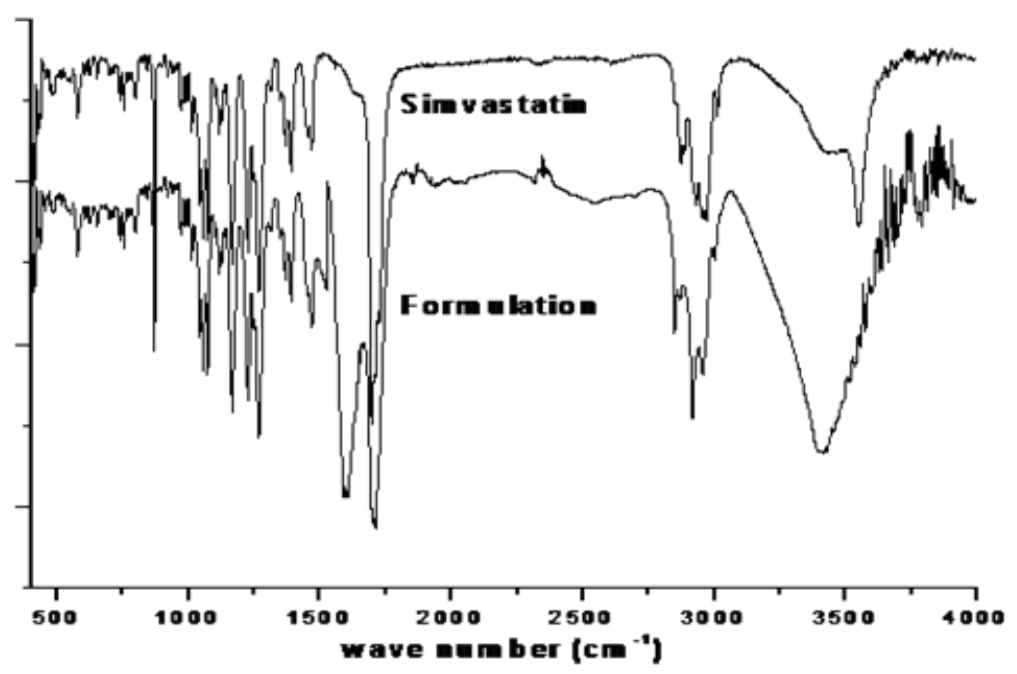

Fig. 1: Comparison of characteristic absorption peaks of simvastatin and formulation-F8

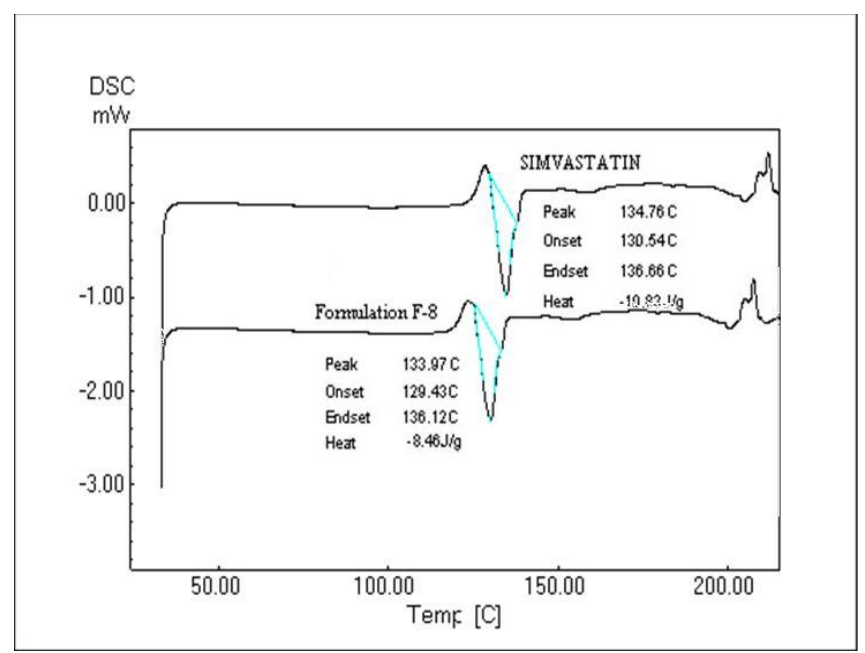

Fig. 2: DSC thermograms of pure drug simvastatin and formulation F8

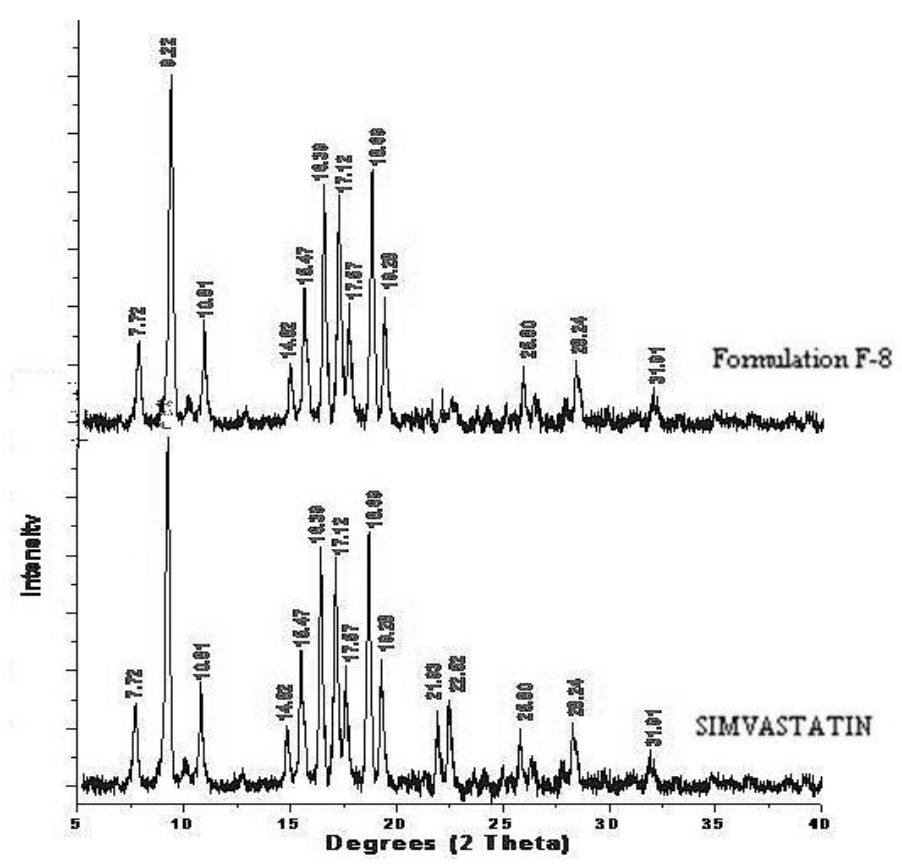

Fig. 3: XRD patterns of pure drug simvastatin and formulation F8 


\section{Flow properties of granules}

The granules prepared for compression of floating tablets were evaluated for their flow properties (table 2). The angle of repose was in the range of 26.61 to $28.86^{\circ}$ with granules containing HPMC $\mathrm{K} 100 \mathrm{M}$ and 24.31 to $32.60^{\circ}$ with HPMC K4M. Bulk density ranged between 0.462 to $0.503 \mathrm{gm} / \mathrm{cm}^{3}$ with granules containing HPMC
$\mathrm{K} 100 \mathrm{M}$ and 0.408 to $0.536 \mathrm{gm} / \mathrm{cm}^{3}$ with HPMC K4M. Tapped density ranged between 0.552 to $0.563 \mathrm{gm} / \mathrm{cm}^{3}$ with granules containing HPMC K100M and 0.478 to $0.677 \mathrm{gm} / \mathrm{cm}^{3}$ with HPMC K4M. Carr consolidation index was found to be 6.02 to 13.59 and Hausner ratio ranged from 0.84 to 1.33 for granules of different formulations. These values indicated that the prepared granules exhibited good flow properties.

Table 2: Flow properties of granules

\begin{tabular}{|c|c|c|c|c|c|}
\hline Code & Bulk density $\left(\mathrm{g} / \mathrm{cm}^{3}\right)$ & Tapped density $\left(\mathrm{g} / \mathrm{cm}^{3}\right)$ & Angle of repose $(\theta)^{*}$ & Carr's consolidation index & Hausner ratio \\
\hline F1 & 0.462 & 0.552 & $26.61 \pm 0.252^{\circ}$ & 11.83 & 1.17 \\
\hline $\mathrm{F} 2$ & 0.503 & 0.563 & $28.86 \pm 0.352^{\circ}$ & 9.90 & 1.11 \\
\hline F3 & 0.455 & 0.535 & $24.31 \pm 0.482^{\circ}$ & 13.59 & 1.15 \\
\hline $\mathrm{F} 4$ & 0.486 & 0.531 & $26.77 \pm 0.285^{\circ}$ & 9.51 & 1.11 \\
\hline F5 & 0.408 & 0.482 & $26.56 \pm 0.317^{\circ}$ & 9.96 & 0.84 \\
\hline F6 & 0.433 & 0.478 & $26.85 \pm 0.159^{\circ}$ & 10.96 & 0.84 \\
\hline F7 & 0.512 & 0.662 & $32.60 \pm 0.269^{\circ}$ & 13.2 & 1.33 \\
\hline F8 & 0.536 & 0.677 & $29.86 \pm 0.421^{\circ}$ & 6.02 & 1.26 \\
\hline F9 & 0.451 & 0.516 & $28.66 \pm 0.376^{\circ}$ & 9.10 & 0.90 \\
\hline
\end{tabular}

$*_{n}=3$, Data presented as mean \pm SD. Rest of the values are given as mean of triplicate.

\section{Buoyancy/floating test}

On immersion in $0.1 \mathrm{~N} \mathrm{HCl}$ solution (pH 1.2), $0.5 \%$ SLS at $37^{\circ} \mathrm{C}$, the tablets floated and remained buoyant without disintegration. Table 3 shows the results of Buoyancy study. From the results, it was concluded that the batch F1and F2 showed good Total floating time (TFT). Formulation F4 and F5 showed good BLT while the formulation F3 and F7 showed less TFT. And the formulation F8 and F9 showed good BLT as well as good TFT. All the batches of tablets were found to exhibit short BLT due to the presence of sodium bicarbonate and citric acid. The tablets with low-viscosity grade HPMC K4M exhibited short BLT and floated for a longer duration as compared with formulations containing high viscosity grade HPMC $\mathrm{K} 100 \mathrm{M}$. Increasing the concentration of HPMC K4M level in the formulations F3, F4, F5, F6, F8, and F9 prolonged the BLT and the total floating time. Thus a combination of sodium bicarbonate $(50$ $\mathrm{mg}$ ) and citric acid (16 mg) with HPMC K4M and HPMC K100M was found to achieve the optimum in vitro buoyancy and float ability.

Table 3: Buoyancy lag time and total floating time

\begin{tabular}{lll}
\hline Formulations & Buoyancy lag time (Sec)* & Total floating time (h)* \\
\hline F1 & $82 \pm 2.32$ & $11.32 \pm 0.02$ \\
F2 & $92 \pm 1.85$ & $11.45 \pm 0.05$ \\
F3 & $28 \pm 2.15$ & $6.15 \pm 0.1$ \\
F4 & $36 \pm 2.68$ & $8.52 \pm 0.08$ \\
F5 & $40 \pm 1.92$ & $8.33 \pm 0.05$ \\
F6 & $58 \pm 3.18$ & $9.15 \pm 0.04$ \\
F7 & $126 \pm 2.65$ & $5.27 \pm 0.06$ \\
F8 & $72 \pm 2.54$ & $9.16 \pm 0.05$ \\
F9 & $80 \pm 1.69$ & $10.21 \pm 0.07$ \\
\hline
\end{tabular}

$*_{n}=3$, Data presented as mean $\pm S D$

\section{Effect of hardness on buoyancy lag time (BLT) or floating lag time (FLT)}

The effect of hardness on buoyancy lag time for batch F8 was studied. The results of floating lag time of tablets with hardness of 4 $\mathrm{kg} / \mathrm{cm}^{2}, 5 \mathrm{~kg} / \mathrm{cm}^{2}, 7 \mathrm{~kg} / \mathrm{cm}^{2}$ and $8 \mathrm{~kg} / \mathrm{cm}^{2}$ were $73,89,118$ and 167 sec respectively. It can be concluded that as the hardness increases, the buoyancy lag time also increases linearly. The optimum hardness for the GRRDS was found to be $4-5 \mathrm{~kg} / \mathrm{cm}^{2}$.

\section{In vitro dissolution study}

The release data obtained for all the formulations is shown in fig. 4. The release of drug from the formulations containing HPMC K100M (F1 and F2) showed very slow drug release whereas tablets containing only HPMC K4M showed complete drug release within $10 \mathrm{~h}$. A formulation containing only NaCMC (F7) showed good release rates at the initial hour but failed to maintain matrix integrity and disintegrated rapidly. Formulations containing both HPMC K4M and NaCMC polymers were found to be more sustained (F8 and F9). These findings are in agreement with the earlier report [22]. It was found that a combination of anionic NaCMC with nonionic HPMC produced a synergistic increase in viscosity. This was attributed to the stronger hydrogen bonding between the carboxyl groups of NaCMC and hydroxyl groups of the HPMC, leading to stronger cross-linking between two gums. To confirm the exact mechanism of drug release from these tablets, the data were fitted according to the equation of Korsmeyer and Peppas, given as $\mathrm{M}_{t} / \mathrm{M}_{\infty}=\mathrm{K} \mathrm{t}^{\mathrm{n}}$ where $\mathrm{M}_{t} / \mathrm{M}_{\infty}$ is the fractional release of drug in time $\mathrm{t}, \mathrm{K}$ is a constant incorporating structural and geometric characteristics of the controlled-release device, and $n$ is the diffusional release exponent indicative of mechanism of release. The value of $\mathrm{n}$ is 0.5 for Fickian transport, more than 0.5 and less than 1 for non-Fickian transport, and 1 for case II transport (zero order); when the value of $\mathrm{n}$ approaches 1 , it may be concluded that the release is approaching zero order. The dissolution data were fit to the above equation by drawing a log-log plot of the fraction released versus time. The ' $n$ ' value was between 0.647 to 0.975 , which indicated that the release followed non-Fickian diffusion mechanism or anomalous transport and suggesting that both diffusions of the drug in the hydrated matrix and chains relaxation process affect the drug release process (table 4). The initial burst effect is probably due to the fact that the gel layer, which controls the release of the drug, needs some time to become effective. The mixture of the two polymers, used as release modulator agents, enables the system to reach a nearly zero-order release kinetic (n for F8 is 0.975). 


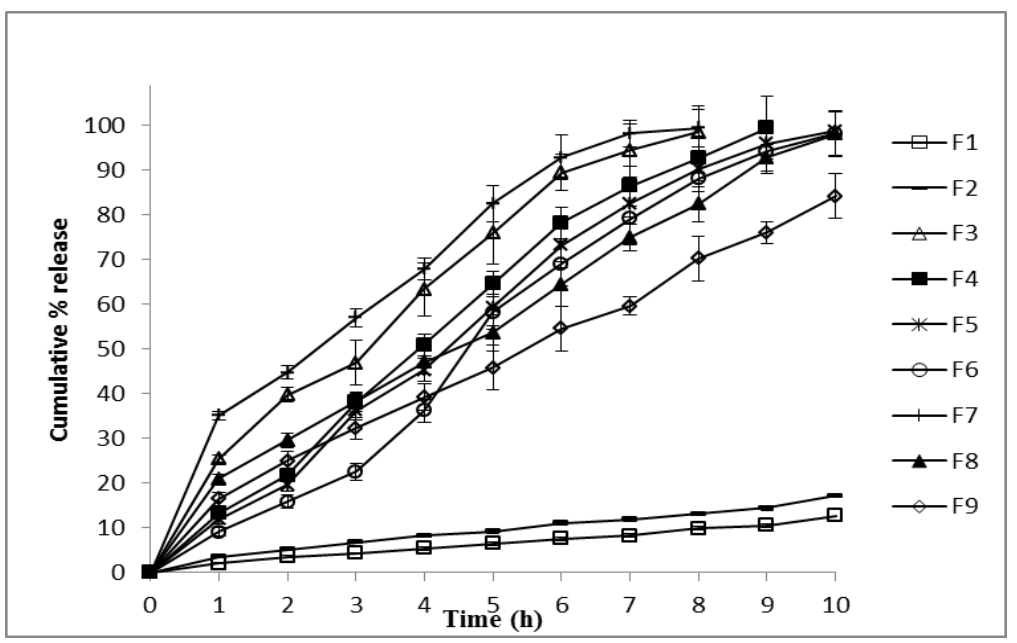

Fig. 4: Dissolution behaviour of the formulations $n=3$, Data presented as mean \pm SD

Table 4: Regression values for zero order and first order of all the formulations

\begin{tabular}{|c|c|c|c|c|c|c|c|}
\hline \multirow[t]{2}{*}{ Formulation } & \multicolumn{2}{|c|}{ Zero order } & \multicolumn{2}{|c|}{ First order } & \multirow{2}{*}{$\begin{array}{l}\text { Higuchi model } \\
\mathbf{r}^{2}\end{array}$} & \multicolumn{2}{|c|}{ Peppas model } \\
\hline & $\mathbf{r}^{2}$ & K value & $\mathbf{r}$ & K value & & n value & $\mathbf{r}^{2}$ \\
\hline F1 & 0.991 & 1.103 & 0.989 & 0.011 & 0.986 & 0.767 & 0.990 \\
\hline F2 & 0.990 & 1.420 & 0.988 & 0.013 & 0.988 & 0.679 & 0.991 \\
\hline F3 & 0.990 & 11.31 & 0.975 & 0.276 & 0.987 & 0.627 & 0.981 \\
\hline $\mathrm{F} 4$ & 0.994 & 6.482 & 0.954 & 0.122 & 0.986 & 0.648 & 0.995 \\
\hline F5 & 0.995 & 6.238 & 0.965 & 0.112 & 0.983 & 0.743 & 0.994 \\
\hline F6 & 0.996 & 5.491 & 0.975 & 0.087 & 0.980 & 0.804 & 0.995 \\
\hline F7 & 0.997 & 11.79 & 0.905 & 0.421 & 0.997 & 0.432 & 0.977 \\
\hline F8 & 0.998 & 7.768 & 0.877 & 0.244 & 0.993 & 0.593 & 0.999 \\
\hline F9 & 0.998 & 7.438 & 0.943 & 0.172 & 0.992 & 0.664 & 0.996 \\
\hline
\end{tabular}

$*_{n}=3$, Average of three determinations

\section{CONCLUSION}

The concept of formulating GDDS containing simvastatin offers a suitable, practical approach to achieving a prolonged therapeutic effect by continuously releasing the medication over an extended period of time $(10 \mathrm{~h})$. This study discusses the preparation of GDDS of simvastatin; the effervescent based floating drug delivery system was a promising approach to achieve in vitro buoyancy. The drug release rate and floating duration of tablets depend upon the nature of the polymer and other added excipients. Thus, the release rate of the drug can be optimised by using different ratios of polymers and other excipients. The formulation F8 achieved the optimized batch and complied with all the properties of the tablets.

\section{ACKNOWLEDGMENT}

The authors are grateful to the Management of PES College of Pharmacy for providing the financial support and encouragement to carry out this project.

\section{CONFLICTS OF INTERESTS}

Declare none

\section{REFERENCES}

1. Todd PA, Goa KL. Simvastatin: a review of its pharmacological properties and therapeutic potential in hypercholesterolaemia. Drugs 1990;40:583-607.

2. Duggan DE, Chen IW, Bayne WF, Halpin RA, Duncan CA, Schwartz MS. The physiological disposition of lovastatin. Drug Metab Dispos 1989;17:166-73.

3. Vickers S, Duncan CA, Chen IW, Rosgay A, Duggan DE. Metabolic disposition studies on simvastatin, a cholesterollowering prodrug. Drug Metab Dispos 1990;18:138-45.
4. McClelland GA, Stubbs RJ, Fix JA. Enhancement of 3-hydroxy-3methylglutaryl-coenzyme A (HMG-CoA) reductase inhibitor efficacy through the administration of a controlled porosity osmotic pump dosage form. Pharm Res 1991;8:873-6.

5. Cheng H, Sutton SC, Pipkin JD, Zetner GM. Evaluation of Sustained/Controlled-release dosage forms of 3-hydroxy-3methylglutaryl-coenzyme an (HMG-CoA) reductase inhibitors in dogs and humans. Pharm Res 1993;10:1683-7.

6. Babu AK, Ramana MV. Development and in vivo evaluation of gastro retentive floating tablets of antipsychotic drug risperidone. Int J Pharm Pharm Sci 2016;8:43-52.

7. Sawant K, Patel P, Patel J, Mundada P. Formulation, optimisation, characterization and in vivo anti-ulcer activity of esomeprazole magnesium trihydrate gastroresistant microspheres. Int J Pharm Pharm Sci 2017;9:273-82.

8. Castellanos RM, Zia H, Rhodes TC. Design and testing in vitro of a bioadhesive and floating drug delivery system for oral application. Int J Pharm 1994;105:65-70.

9. Shah HP, Prajapati ST, Patel CN. Gastroretentive drug delivery systems: from conception to commercial success. J Crit Rev 2017;4:10-21.

10. Rao GK, Mandapalli PK, Manthri R, Reddy VP. Development and in vivo evaluation of gastro retentive delivery systems for cefuroxime axetil. Saudi Pharm J 2013;21:53-9.

11. Kharwade RS, More SM, Mahajan UN. Formulation and evaluation of gastroretentive floating tablet using hibiscus rosa-sinensis mucilage. Asian J Pharm Clin Res 2017;10;444-8.

12. Upadhye AA, Ambike AA, Mahadik KR, Paradkar A. Application of ion exchange resin in the floating drug delivery system. Drug Dev Ind Pharm 2008;34:1117-24.

13. Klausner EA, Lavy E, Friedman M, Hoffman A. Expandable gastroretentive dosage forms. J Controlled Release 2003; 90:143-62. 
14. Baumgartner S, Kristl J, Vrecer F, Vodopivec P, Zorko B. Optimization of floating matrix tablets and evaluation of their gastric residence time. Int J Pharm 2000;195:125-35.

15. Manna S, Jayasri K, Annapurna KR, Kanthal LK. Alginate based gastro-retentive raft forming tablets for enhanced bioavailability of tinidazole. Int J Appl Pharm 2017;9:16-21.

16. Chavanpatil M, Jain P, Chaudhari S, Shear R, Vavia P. Development of sustained release gastroretentive drug delivery system for ofloxacin: in vitro and in vivo evaluation. Int J Pharm 2005;304:178-84.

17. Streubel A, Siepmann J, Bodmeier R. Floating matrix tablets based on low density foam powder: effects of formulation and processing parameters on drug release. Eur J Pharm Sci 2003;18:37-45

18. Dave BS, Amin AF, Patel MM. Gastro retentive drug delivery system of ranitidine hydrochloride: formulation and in vitro evaluation. AAPS PharmSciTech 2004;5:1-6.
19. Nur OA, Zhang JS. Captopril floating and/or bioadhesive tablets: design and release kinetics. Drug Dev Ind Pharm 2000;26:965-9.

20. Narendra C, Srinath MS, Babu G. Optimization of bilayer floating tablet containing metoprolol tartrate as a model drug for gastric retention. AAPPS PharmSciTech 2006;7:E1-E7.

21. Zhang Y, Zhang J, Jiang T, Wang S. Inclusion of the poorly watersoluble drug simvastatin in mesocellular foam nanoparticles: drug loading and release properties. Int J Pharm 2011;40:118-24.

22. Chavanpatil M, Jain P, Chaudhari S, Shear R, Vavia P. Novel sustained release, swellable and bioadhesive gastro retentive drug delivery system for ofloxacin. Int J Pharm 2006;316:86-92.

\section{How to cite this article}

- Manjunath PN, Satish CS, Vasanti S, Preetham AC, Naidu Ras. Formulation and evaluation of simvastatin gastro retentive drug delivery system. Int J Appl Pharm 2017;9(3):55-60. 